\section{Bouchra Khalili}

Centro Andaluz de Arte Contemporáneo, Sevilla

Del 2 de noviembre de 2017 al 4 de marzo de 2018*

La proximidad geográfica entre el Magreb y la Península Ibérica ha marcado históricamente la percepción que la sociedad española tiene sobre sí misma. Desde las mitologías fundacionales de España como Estado-nación (la Reconquista) hasta el papel determinante que los protagonistas de las guerras coloniales han tenido en nuestra historia reciente (los militares africanistas, el golpe de 1936, la Guerra Civil, la dictadura franquista), el moro ha estado siempre ahí, como una pieza indispensable en el constructo de nuestra identidad colectiva. $Y$ el hecho de que actualmente el PIB de España multiplique por doce el de Marruecos -y que sea la hispano-marroquí la frontera más desigual de toda la Unión Europea- tampoco ayuda a poner en cuestión el rol tradicional que ha jugado y aún juega el vecino del Sur a manera de espejo en negativo de quienes creemos ser. El que los españoles podamos pensarnos como europeos tout court precisa de la existencia de un límite inequívoco, que ha encontrado históricamente en Marruecos el Otro ideal, en el que imaginariamente reflejarnos, por contraste, como una sociedad moderna, tolerante, dinámica, racional, científica, laica,... frente a la irracionalidad, el inmovilismo, la intransigencia religiosa, el fatalismo y el atraso que el estereotipo orientalista descarga sobre el otro lado del Estrecho.

A los cuatro arraigados estereotipos que ya a mediados del siglo XX señalara Paul Balta ${ }^{1}$ en el patrón dominante de la representación del mundo árabe islámico en Occidente -a saber, el fanático integrista, el terrorista desalmado, el despótico, infantil y caprichoso emir del Golfo y, por fin, el pobre e inculto trabajador inmigrante- quizá no cabría añadir más que la tenacidad de su progresivo agrandamiento cuando estos prejuicios se aplican a las mujeres: entonces se multiplican y refuerzan al superponerse al tan bienquisto cliché de la mujer como sumisa y silenciosa víctima.

En su versión menos hostil -esto es, las guías y folletos turísticos y revistas del ramo o los reportajes televisivos de los canales de ocio y viajes- árabes y musulmanes suelen comparecer adornados de virtudes tales como la cortesía y la hospitalidad, pero también en una actitud ajena respecto al devenir del tiempo, como estancados en algún momento de la historia, poco preciso pero definitivamente localizado en el pasado: como elementos de una decoración pintoresca destinada a destacar, en su diferencia, nuestra modernidad, nuestra indiscutible superioridad.

El papel que las producciones culturales juegan en el proceso de exotización e inferiorización del otro es evidente. En este sentido es proverbial la ignorancia generalizada acerca de las expresiones artísticas del mundo árabe contemporáneo. Por ejemplo, los escasos escritores árabes que nos llegan rara vez no lo hacen doblemente traducidos -del francés, sobre todo- $y$ tras su previo éxito comercial en Europa. Y lo mismo sucede con el cine. Salvo en los pocos festivales dedicados al cine árabe (Amal, en Santiago de Compostela) o africano (Tarifa, Barcelona) o, de modo aún más genérico, a los cines del Sur global (Granada), lo poco que alcanzamos a conocer viene indefectiblemente precedido por la fama de su galardón en Venecia o en Cannes. Y otro tanto si habláramos de música: siendo escasas las oportunidades que tenemos de disfrutar de la misma, cuando esto sucede, normalmente se trata de música tradicional, sea clásica o folclórica, jamás contemporánea. Y en los catálogos de las bibliotecas y librerías -o en los buscadores de internet- «arte árabe» remite casi sin excepción a ejemplos de arquitectura -sobre todo religiosa-, a caligrafía, a cerámica decorativa, etc., mayoritariamente datadas hace siglos.

En este contexto asociar la palabra «Marruecos» a la expresión «arte contemporáneo» suena como un oxímoron. Por supuesto que no se puede hablar de un arte contemporáneo marroquí de modo unitario ni homogéneo -exactamente igual que acerca de cualquier otra nacionalidad-, pero lo más habitual es que si alguien ha visto alguna vez obra de artistas marroquíes vivos ha sido en exposiciones colectivas sin más tema que ese mismo, el «arte contemporáneo marroquí» o, aún más a granel, «árabe». Y la cosa empeora cuando se toman como pretexto unos más bien forzados "encuentros» en busca de supuestas «afinidades" y «paralelismos» con artistas españoles -de preferencia, 


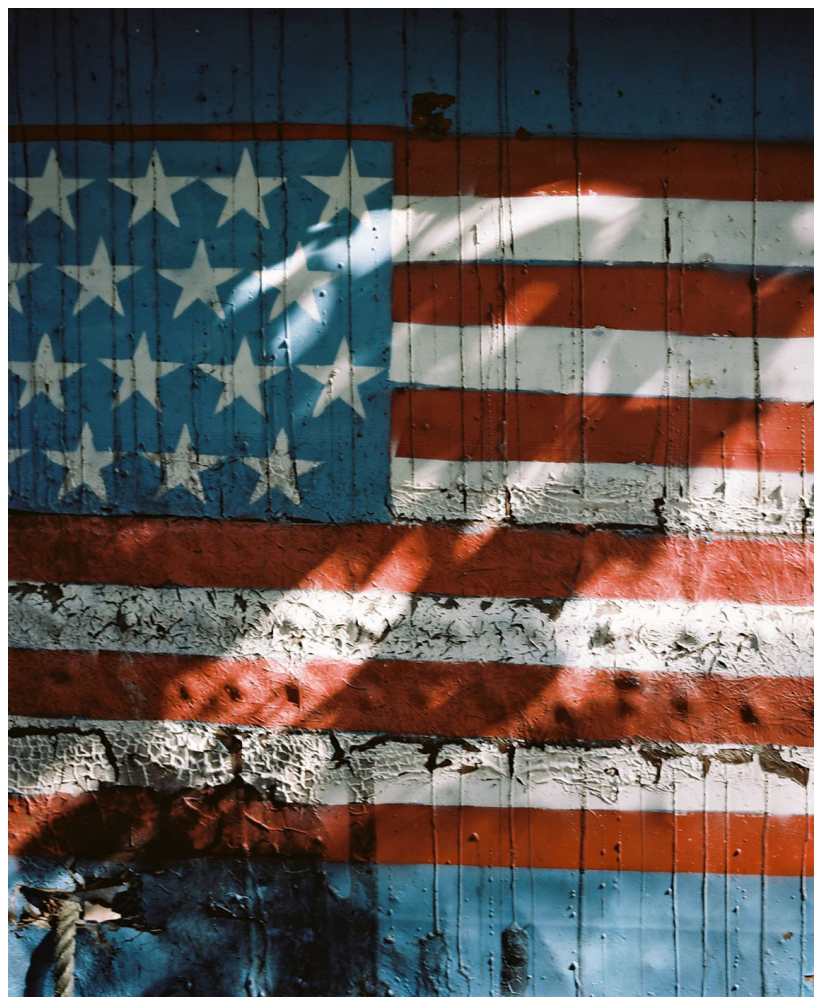

1. Bouchra Khalili, The Wet Feet Series. Lost Boats. Flag, 2012 (C Bouchra Khalili-Galerie Polaris, París

pintores-, de quienes los marroquíes serían aplicados epígonos, seguidores o ecos. Siempre apoyados en nuestra propia vara de medir. Y no es menos lamentable que en estas exposiciones se repitan una y otra vez los mismos pocos nombres, no sólo de artistas sino de curadores y directivos de las asociaciones que las organizan, y que llegan a intercambiarse estos distintos roles, o incluso a simultanearlos, apareciendo como artistas en muestras de las que ellos mismos son comisarios. Al tufo del abuso colonialista no le falta siquiera el paternalismo de la selección de coloristas autores autodidactas, ni de obras caracterizadas por una cierta estética primitivista, expresionista o naif, nimbada de la lírica de «los encantos de antaño», todo, se diría, sin otro fin que alimentar la percepción de encontrarnos ante un arte «subdesarrollado», por más que «auténtico».

No hace tanto tiempo se consideraba que el lugar apropiado para mostrar la obra de artistas marroquíes eran las salas del Museo Etnográfico². Hoy, y sin abandonar del todo ese marco de curiosidad excéntrica -incluso en los casos en que su presencia no es en absoluto extraña en los circuitos de arte contemporáneo internacional- solo muy recientemente se ha podido empezar a contemplar en salas de exposición españolas obra de artistas marroquíes actuales. Y si el número se acorta cuando hablamos de artistas marroquíes a quienes se haya dedicado una exposición personal en una galería, menor es si se trata de mujeres artistas $^{3}$. Y todavía más excepcional es si se trata de un museo. Con los dedos de una mano basta y sobra: Latifa Echakhch en el Macba (Barcelona, 2011), Yto Barrada en Tabakalera (Donosti, 2016)... La norma, ya hemos dicho, es que la circulación entre nosotros de las producciones culturales del Marruecos contemporáneo -y no sólo de arte: de cualquier tipo- viene determinada por su aprobación previa -un león de oro, un goncourt- por parte de los centros de poder autorizados a este fin, es decir, que su legitimación depende, en última instancia, de su grado de traducibilidad a la lógica cultural hegemónica.

No es ajena a esta circunstancia la obra de Bouchra Khalili (Casablanca, 1975), que si bien no es desconocida en España -pues ha menudeado en exposiciones y muestras de video por lo menos desde 2003-, solo después de haber merecido exposiciones individuales en el MoMA (2016), la bienal de Venecia (2013) o la última Documenta XIV (Kassel, 2017) presenta ahora en Sevilla, en el Centro Andaluz de Arte Contemporáneo, esta exposición, coproducida con el Jeu de Paume de París.

Esta oportunidad para romper con el habitual paradigma anecdótico y acercarse a un conjunto coherente de piezas es verdaderamente extraordinaria. Se reúne aquí una selección de trabajos realizados entre 2008 y 2017 en distintos y distantes lugares del planeta -Argel, Florida, Hamburgo, Génova, Nueva York, Atenas-, cuya mera enumeración da cuenta ya de una movilidad que se ha convertido en característica de cierta producción artística contemporánea, y que no puede dejar de interpretarse en relación con las exigencias de deslocalización propias de la globalización del capitalismo neoliberal, que requiere una fuerza de trabajo permanentemente disponible, errante -también de artistas: mi patria es mi laptop, que en sintonía con esa transportabilidad, exhibe entre su rasgos distintivos una progresiva desmaterialización de sus soportes, que se se ven reducidos prácticamente a la fotografía y el vídeo, contenidos de fácil transmisión a través de archivos digitales. 


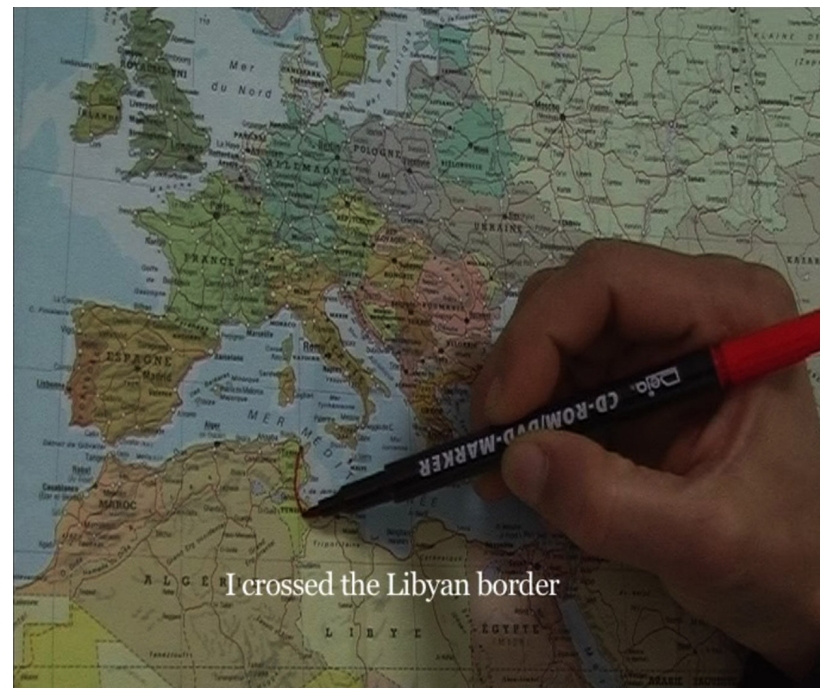

2. Bouchra Khalili, The Mapping Journey Project, \#2, 2008 @ Bouchra Khalili-Galerie Polaris, París

El trabajo de Bouchra Khalili puede entenderse bajo esta perspectiva, que ha recuperado y revalorizado el léxico formal de las prácticas del arte conceptual del pasado siglo. La artista, sin embargo, al mismo tiempo se desmarca de ese legado gracias a su distanciamiento respecto a uno de sus formatos más tópicos, el archivo. Frente a la banalmente abrumadora exhibición de documentación, Khalili la somete a un sofisticado proceso de edición, de selección y montaje que, además, sabiamente se oculta tras la aparente naturalidad de su puesta en escena. Su extrema sobriedad, su aspecto de inmediata transparencia abre la puerta a un campo de tensiones cuya complejidad se ve activada con una eficacia tan formidable como sutil a través de procedimientos atravesados por el cine documental y la experimentación teatral.

En este pulcro y a la vez complejo juego de espejos -que rechaza al espectador apresurado, al paseante-turista habitual de los museos hoy día- está construido por vídeos y fotografías en los que el protagonista es, en gran medida, una humanidad invisible y muda. O mejor, que históricamente ha sido invisibilizada y silenciada. No hay rastro en las imágenes del sudor o la sangre: cuerpo ausente. $O$ del que se han borrado las señales de la violencia del globalizado régimen neocolonial. En ocasiones, no vemos a quien habla; en otras, quien lo hace repite palabras que no son suyas; otras

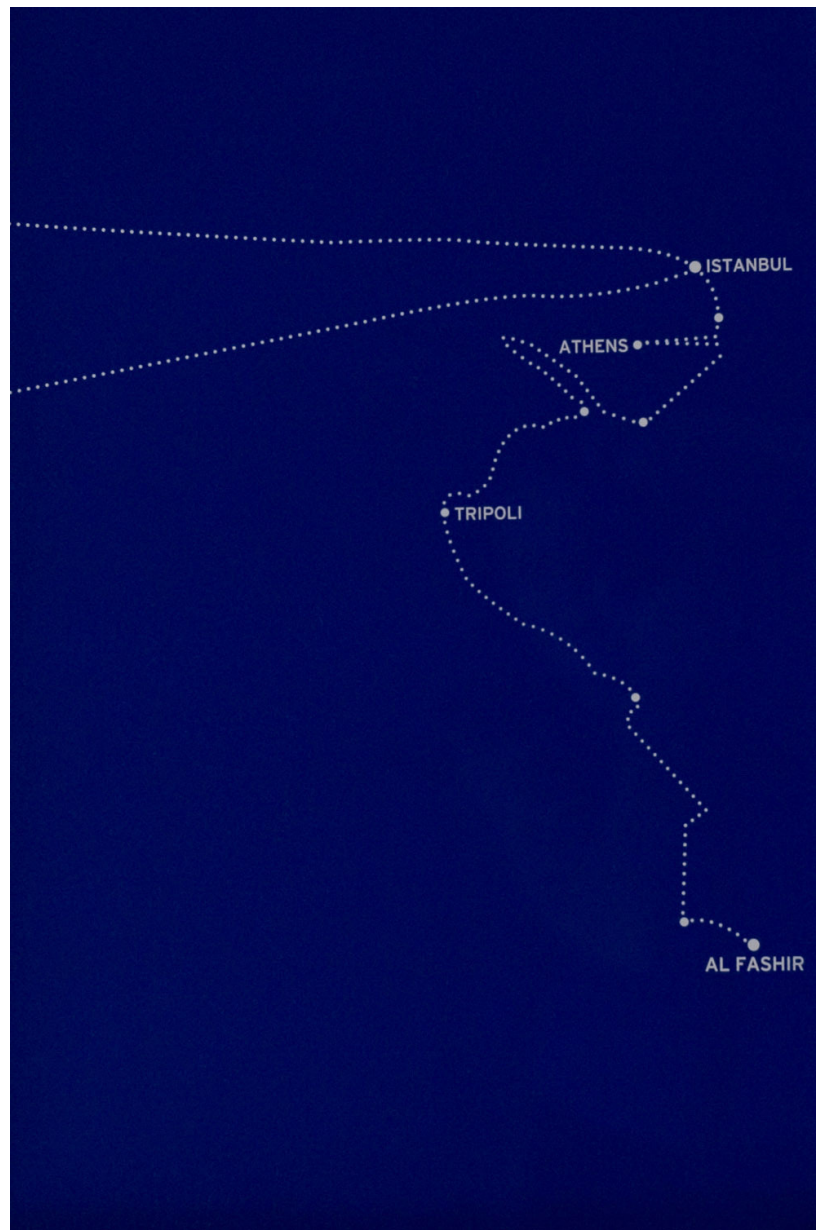

3. Bouchra Khalili, The Constellations, 2011 C Bouchra Khalili-Galerie Polaris, París

veces, lo que escuchamos es la banda sonora de una película cuya visión se nos oculta; en su lugar, lo que vemos son los rostros, las miradas atentas de quienes la contemplan. Redoblando nuestro rol de inmovilizados espectadores, miramos a quien mira, a quien recita un discurso memorizado - ¿letra muerta?- de Mahmoud Darwish, de Aimé Cesaire, de Abd el Krim el Jatabi, de James Brown..., una polifonía que se encarna en la lenguas rotas de solicitantes de refugio y migrantes sin papeles, de víctimas de la frontera que hablan sobre la frontera y en la frontera misma que precede y persigue al espectro de la alteridad racializada.

En las referencias textuales de la obra de Khalili sobresalen los héroes de un tiempo que entendió escribir y luchar como una misma cosa, el texto como arma y como campo 
de batalla. Pero, en lo que de otro modo podría parecer una elegía por unas aspiraciones utópicas dolorosamente eliminadas de nuestro horizonte histórico, gracias a su apropiación estratégica de la lengua del amo -el broken English o las infinitas creolizaciones pero también de los códigos dominantes en el arte global- resuena la vindicación del gran Kateb Yacine: «la langue française est un butin de guerre».

Transvernácula, nómada y desterritorializada, toda la obra de Khalili gira en torno a los conceptos de identidad, de Estado-nación, de ciudadanía, derechos, exilio, migraciones, fronteras... Sus ejes básicos son el desplazamiento y la traducción. Recurriendo a la elipsis, el fuera de campo y las citas textuales y testimonios, las obras zigzaguean -lo mismo que quien busca esquivar un check point detrás de otro- entre la cita erudita y la memoria personal. Igual que los mapas son atravesados por las cicatrices y el relato de las supervivientes del viaje, que han desafiado desde su propio cuerpo una geografía construida por el capital y contra la vida, las formas se ven subvertidas por un uso que las desmonta y vuelve a armar como escritura de resistencia para unas identidades en tránsito. Bouchra Khalili, mujer ella misma en la diáspora -formada como artista en Francia-, fuerza un lenguaje al que interroga y obliga a pronunciarse sobre su condición política. Quizá la definición más apropiada la ha ofrecido ella misma: «no se trata de un documental ni una obra de ficción, sino de una hipótesis»4.

Rogelio López Cuenca

\section{Notas}

* Una versión más breve de este texto se publicó bajo el título de de «Mi patria es mi laptop» en El País (Babelia) el 27 de noviembre de 2017.

1 Balta, Paul, «Los medios y los malentendidos euroárabes», en El Mundo Árabe y su imagen en los medios, Madrid, 1994.

2 Fernández Parrilla, Gonzalo. "El arte llevado a la vida», en Said Messari, Obra gráfica 1988-2000, Madrid, 2001.

3 Amina Bebouchta ha expuesto, por partida doble, en 2013 y 2015, en la galería Sabrina Amrani, de Madrid, especializada en arte contemporáneo de Asia África y América Latina.

4 http://www.bouchrakhalili.com/the-tempest-society-video-2017. 